\title{
Applying thermodynamics to understand the links between energy, information, structure and biodiversity in human-transformed landscapes
}

\author{
Joan Marull ${ }^{1}$, Joan Pino ${ }^{2}$, Yolanda Melero², Raimón Puig ${ }^{1}$, and Enric Tello ${ }^{3}$ \\ ${ }^{1}$ Autonomous University of Barcelona \\ ${ }^{2} \mathrm{CREAF}$ \\ ${ }^{3}$ University of Barcelona
}

May 5, 2020

\begin{abstract}
Both in natural and in human-made agroecosystems, biodiversity can be understood as a direct function of landscape complexity and an inverse function of energy dissipation. The main difference between them is the external energy driven by farmers' information that transforms natural ecosystems into agroecosystems. If this is true, can an energy-information-structure model predict biodiversity in cultural landscapes? To that aim, we have developed an Energy-Landscape Integrated Analysis (ELIA) that measures the energy stored through internal loops (E) and the information incorporated into the energy network of agroecosystems (I), to correlate them with the resulting patterns and processes of cultural landscapes (L). This approach integrates the energy flow accounting of agricultural landscapes from an Ecological Economics point of view, and the Landscape Ecology metrics that assess the functional structure of their land covers. ELIA uses the E-I-L indicators to predict the biodiversity location in human-transformed landscapes. We have tested this model on biodiversity data through two different taxonomic groups, butterflies and birds, in the metropolitan region of Barcelona (Spain). The results show positive relationships between butterflies and birds species richness with ELIA, and especially with the variable I: information. This emphasizes how different strategies of agricultural management combined with nature conservation can be approached at some optimal points in the relationship between the energy-information-structure of cultural landscapes and the biodiversity located on them. The ELIA modelling opens a new research agenda that will be very useful for designing more sustainable agroecosystems, metropolitan green infrastructures and land use policies.
\end{abstract}

\section{Significance Statement}

The ELIA model comprehensively assesses the links between the energy and information flows driven by farming, the land cover patterns they imprint, and the species richness in human-transformed landscapes. When this model is used as a predictor of biodiversity, the information-based redistribution of energy flows becomes a primary indicator of the key role of farmers' knowledge and labour in maintaining the ecological functionality of biocultural landscapes by means of a subtle and historically changing human-nature relationship. TheELIA modelling and results are very useful for land-use policies aimed at addressing the energy-food-biodiversity trilemma currently posed at global scale.

\section{Main Text}

\section{Introduction: Biodiversity in human-transformed landscapes}

For centuries, global human-driven Land Use and Cover Change (LUCC) has spread the so-called 'anthropogenic habitats' in many regions, like the Mediterranean, thus determining biodiversity and ecosystem functioning in human-transformed landscapes $(\mathbf{1})$. The impacts have been manifold, strongly differing from 
the mosaic landscapes of past and present organic mixed farming adapted to site-specific natural endowments, up to the land cover homogenization driven by industrial farming and animal feeding reliant on fossil fuels combined with spontaneous reforestation ensuing rural abandonment $(2, \mathbf{3}, \mathbf{4})$. Effects of LUCC on biodiversity are largely known $(\mathbf{5}, \mathbf{6})$, and they include a general decrease in species richness but also changes in species composition due to rarefaction of habitats specialists and expansion of generalists and cosmopolitan species, as well as invasions by alien species $(\mathbf{7}, \mathbf{8})$ through increasing propagule pressure and disturbance levels $(\mathbf{9}, \mathbf{1 0})$. All these impacts lead to biotic homogenization in most-human transformed regions (11).

Biodiversity components associated to human-transformed landscapes are clear examples of these changes. For example, population decline of most bird and butterfly species is believed to be linked to the loss and fragmentation of natural habitats, but also to the abandonment of traditional land-use management in rural areas that led to both agricultural intensification and forest encroachment $(\mathbf{1 2}, \mathbf{1 3})$. These LUCC effects added to other global change components, like climate change $(\mathbf{1 4}, \mathbf{1 5})$ combined with homogenization of cultural landscapes (16 ). Habitat specialists often are the most negatively affected, while generalists can even take profit of them (17).

As a result, human-transformed landscapes are the outcome of a shifting interplay between the spatial patterns of land-use types driven by the energy flows of human activity, and their associated ecological processes $(18,19)$. A widely acknowledged consensus in conservation biology, framed in the intermediate disturbance hypothesis $(\mathbf{2 0})$, points out that landscape heterogeneity is key to maintaining biodiversity peaks at intermediate disturbance levels through the interaction between the ecosystem patch diversity and the ecological requirements to activate the dispersal abilities of species that come from less disturbed patches or colonize the most disturbed ones $(\mathbf{2 1}, \mathbf{2 2})$. However, the outcome also depends on the intensity and spatial distribution of the anthropogenic socio-metabolic flows at play $(\mathbf{2 3}, \mathbf{2 4})$. This recurrent interaction between landscape patterns and socioecological pressures opens a research field on how the complexity of the energy flows driven by farming, livestock rearing, and forestry 'imprint' diverse spatial patterns of human land-uses that give rise to heterogeneous or homogeneous landscapes capable to house different biodiversity levels $(\mathbf{2 5}$ ,26).

The fundamentals of this research agenda can be found in Morowitz's theorem that says that a flow of energy through a system is a necessary and sufficient condition for generating an organized structure, although ephemeral in time (27). The structures of living systems that emerge and evolve towards a self-reproducing complexity allow to keep information organized and to transfer energy with higher efficiency away from thermodynamic equilibrium (28). Without doubt, this increase in internal complexity is achieved by exporting entropy to the environment, as any living organism is an energy dissipative structure with multiple metabolic cycles interrelated through a space-time heterogeneous base (29). This thermodynamic concept of organisms has close similarities to ecosystems' sustainability, which is directly related to information-complexity and inversely to entropy. When a living system becomes more complex it is also metabolically more efficient because it increases the internal information instead of its energy intake, thereby also reducing external entropy $(30)$.

Margalef principle indicates that ecosystems succession tends to a decrease in the photosynthetic Net Primary Production (NPP) growth rate. In other words, entropy combined with information increases diversity, not the production of uniformity $(\mathbf{3 1})$. In the same vein, complex agroecosystems can store more energy and information at some points that reduce internal entropy, thanks to the exploitation of other spaces of lower complexity but larger NPP production rate within a joint encompassing landscape functional structure. Many traditional Mediterranean agroecosystems were the result of this type of balance between exploitation and conservation through the spatial localization of different gradients of human intervention, a wise intermediate disturbance pattern resulting in heterogeneous landscape mosaics (32).

The combination of an energy-flow pattern driven by complex information on how energy is redistributed across space is a good starting point for modelling the human-landscape relationships. According to Margalef (31), 'the relationship between the external energy inputs and the dimensions that characterize the spatial 
patterns of its distribution' gives rise to the functional structure of landscape mosaics capable to host higher biodiversity than other homogeneous land covers. In order to test this hypothesis, Marull et al. (33 ,54 ) developed an Energy-Landscape Integrated analysis (ELIA ) of agroecosystems which accounts both the investment of energy stored within $(E)$ and the information held in the whole network of socio-metabolic energy flows $(I)$, to correlate their interplay $(E \cdot I)$ with the functional structure of the resulting cultural landscape $(L)$. Then, we use here this energy-information-structure model (Fig. 1$)$ to predict the locations of two important biodiversity components, butterflies and birds, in the human-transformed landscapes here accounted as an empirical example (31). The aim is to test Margalef's hypothesis that the complex landscape mosaics of traditional organic agriculture were, and continue to be, good for biodiversity conservation. This means discussing if the energy reinvested and redistributed by farming-driven metabolic flows can lay the foundations to study the linkages that exist between social metabolism, landscape ecology and biodiversity, to better inform sustainable-oriented land use policies.

[Insert Figure 1 here]

Testing Margalef'f hypothesis requires specifying and accounting the ecological disturbance exerted by the information-driven external energy that farmers incorporate to the landscape. The Human Appropriation of Net Primary Production (HANPP) is a quantitative estimate of the potential annual biological productivity reduced by human activities $(\mathbf{3 4}, \mathbf{3 5})$. It provides a first approach to the interplay between the anthropogenic disturbances and the wildlife ability to withstand them. Intermediate HANPP values can maintain greater biodiversity in human-modified landscapes than higher ones that would largely decrease habitat differentiation and the provision of enough food chains free from human colonization (36 ). On this light, Marull et al. (33 ) developed an Intermediate Disturbance Complexity (IDC) model to assess how different levels of anthropogenic disturbance at regional scale affect landscape functional structure. Results show a hump-shaped relationship between landscape complexity, free NPP available for non-domesticated species, and biodiversity levels $(\mathbf{3 3}, \mathbf{3 7})$. However, this strongly depends not only on the overall flux balance of photosynthetic biomass but on the intensity and distribution of socio-metabolic flows associated to either land-use mosaics or homogeneous land covers of agroecosystems $(23, \mathbf{2 4}, \mathbf{3 8})$.

The ELIA modelling goes a step forward from the previous $I D C$ explorations of the links between intermediate levels of socio-metabolic human disturbance and the ecological functioning of cultural landscapes carried out at regional scale $(\mathbf{3 7})$. It measures $E$ as the quantity of energy remaining in the agroecosystem, and $I$ as the complexity of the network of flows which allows farmers to reproduce the landscape fund components thanks to the information embedded in the system. Both indicators, $E$ and $I$, bring to light how the energyinformation interplay gives rise to human-transformed landscapes. They do so by relating them to $L$, the landscape ecology metrics that assess the 'imprint' of the energy flows driven by farmers. We surmise that the interplay between $E$ and $I$ jointly leads to complexity, understood as a balanced level of intermediate self-organisation (39). We also assume that the complexity of energy flows $(E \cdot I)$ is related to the landscape functional structure $(L)$. The cyclical nature of these matter-energy flows is relevant in order to grasp the emergent complexity and the greater information held within agroecosystems, since they imply an internal maximisation of some less-dissipative fractions of societal metabolism. The complexity and information carried out by these energy loops lay the foundations to better understand and develop more sustainable human-managed landscapes.

\section{Results: Testing the ELIA model against biodiversity empirical data}

Our study provides evidence that depending on the interplay between energy storage and its distribution pattern $(E \cdot I)$, the societal metabolic flows driven by farming imprint different landscapes $(L)$ where agroecosystems may either enhance or decrease populations and species richness of butterflies and birds in the Barcelona Metropolitan Region. Significant results of Structural Equation Models (SEM) are summarized in Fig. 2 and $\mathbf{3}$, while complete data are shown in Tables S1 to S8 inAnnex A of the Supplementary Information .

[Insert Table 1 here] 
The butterfly's Principal Component Analysis (Table 1 ) shows that the first factor is the land cover composition of the landscape ( $\mathrm{Cm} 1 ; 43.9 \%$ of variance) that obtains higher loading for forest, while the second $(\mathrm{Cm} 2 ; 35.5 \%)$ presents greater loading for cropland. The first component of land metrics which assesses landscape configuration through land metrics (Cn1; 72.4\%) shows negative loadings for diversity and fragmentation and positive loadings for grain size and connectivity, while the second component is more heterogeneous and contributes much less to explain the variance $(\mathrm{Cn} 2 ; 12.2 \%)$ despite being mostly associated to connectivity metrics (including effective mesh size).

\section{[Insert Figure 2 here]}

The SEM results (Fig. 2 ) show that total butterfly observations (TBOB) are positively associated to ELIA values while species richness (TBSR) does not show any significant correlation with this model. ELIA is negatively associated to $\mathrm{Cm} 1$ in the TBSR model, but not in the TBOB one. In both models, Cm1 and $\mathrm{Cn} 1$ were negatively associated. The $\mathrm{R}^{2}$ for the endogenous variables of TBSR and TBOB models were 0.316 and 0.266 respectively. When disentangling the effects of ELIA components $(E, I$ and $L), I$ shows a positive association with both TBSR and TBOB, while $E$ and $L$ are only significant and positively associated to TBOB. Landscape composition $(\mathrm{Cm})$ and configuration $(\mathrm{Cn})$ are not significantly associated to any biodiversity component, yet $\mathrm{Cm} 1$ is negatively associated to ELIA values in both models and $\mathrm{Cm} 2$ is negatively associated to $I$ only in the TBOB model. The $\mathrm{R}^{2}$ for the endogenous variables of TBSR and TBOB are 0.420 and 0.334 respectively.

In the bird's Principal Component Analysis, the first factor of landscape composition (Cm1;39.3\% of variance) shows higher loading for forest, while the second factor $(\mathrm{Cm} 2 ; 31.8 \%)$ has greater loadings for scrubland and cropland (Table 1 ). The first factor of landscape configuration (Cn1; 53.6\%) records higher (negative) loadings for landscape diversity and fragmentation, while the second (Cn2; 27.3\%) shows greater (positive) association for ecological connectivity and effective mesh size.

[Insert Figure 3 here]

The SEM results (Fig. 3 ) show that breeding bird species richness (BBSR) and wintering bird species richness (WBSR) are positively related to ELIA values and $\mathrm{Cm} 2$, and negatively related to Cn2. ELIA is negatively related to $\mathrm{Cn} 1$ in both models, and with $\mathrm{Cm} 1$ only in the BBSR model. $\mathrm{Cn} 2$ and $\mathrm{Cm} 1$ are also negatively associated in this model. The $\mathrm{R}^{2}$ for the endogenous variables of BBSR and WBSR are 0.244 and 0.210 respectively. If we disentangle the effects of $E L I A$ components $(E, I$ and $L), I$ and $E$ are positively and negatively correlated, respectively, with both BBSR and WBSR. $L$ is only associated negatively to WBSR. $E$ is negatively associated to $\mathrm{Cm} 2$ in both models, and to $\mathrm{Cm} 1$ only in the BBSR model. $L$ and $\mathrm{Cm} 1$ are negatively associated in this last model. The $\mathrm{R}^{2}$ for the endogenous variables of BBSR and WBSR are 0.321 and 0.329 respectively.

\section{Discussion: Confronting ELIA results with Margalef's hypothesis}

We have checked Margalef's hypothesis on the capacity to host high biodiversity in cultural landscape mosaics resulting from a complex distribution of external energy flows of farming, by testing the links of the spatial energy-information structure with the species richness of butterflies and bird populations observed in the Barcelona Metropolitan Region $(\mathbf{3 1}, \mathbf{3 7}, \mathbf{4 0})$. The results confirm that agroecosystems are key to halt the serious decline of butterfly populations in Europe (41), which can also be taken as proxy of many other current biodiversity threats (42). The importance of the energy landscape redistribution $(I)$ carried out by farmers is coincident with recent research highlighting that the worrying decline of common birds' populations in European cultural landscapes is related to the abandonment of long land use patterns of human-made agroecosystems (43).

The Energy-Landscape Integrated Analysis has demonstrated to be an efficient predictor of butterfly and bird locations in the human-transformed landscapes studied. Indeed, ELIA can better predict these biodiversity locations than landscape composition or configuration metrics taken alone. Farmers' uneven spatial distribution of the biomass energy flows $(I)$ of agroecosystems appears to be the key factor to explain 
butterfly observations and species richness, but also breeding and wintering species richness. This is an important outcome that points out to the role of farmers' knowledge in designing the ecological functionality of biocultural landscapes through a subtle human-nature relationship (40). It confirms that the interplay between the energy reinvested $(E)$ and redistributed $(I)$ by farmers affects the landscape functional structure $(L)$ and its associated biodiversity through the harnessing of biomass flows that loop within these human-transformed landscapes.

The analytical advances and positive results obtained mean that the usual methodology of energy flow analysis of social metabolism and the classical landscape ecology metrics need to be adapted, enlarged and integrated to account for the complex cyclical character of human-driven land use changes in cultural landscapes. Traditional farm systems with a solar-based metabolism tended to organise their land usages according to different gradients of spatiotemporal intensity, keeping an integrated management of different land patches because their whole subsistence depended on the endurance of that landscape functional structure (40). In order to offset the energy lost in the inefficient human exploitation of animal bioconversion, on which they had to rely to obtain traction and manure, past organic farmers kept livestock breeding carefully integrated with cropland, pastureland and forestland (44).

While the traditional organic farm management scheme of closing energy cycles within complex agroecosystems led to landscape mosaics which allow a land sharing strategy for biological conservation (45), the agroindustrial farm systems that rely on external flows of inputs coming from underground fossil fuels have enabled society to overcome the age-old energy dependency on bioconverters (46 ). As a result, integrated land-use management was no longer necessary, and overcoming that former necessity led to the loss of its agroecological virtues. Nowadays biodiversity conservation in land matrices mostly occupied by cultural landscapes cannot be guaranteed only through the protection of natural areas (land sparing) in exchange for promoting an ever more intensive industrial agriculture. It requires, instead, an improvement of the ecological connectivity and functionality of the whole land matrix by recovering and enhancing agroecology landscape mosaics (land sharing). This also means to start scaling up the agroecosystems' functioning at the landscape level to cope with and offset the land cost of sustainability (47). Therefore, the integration between social metabolism and landscape ecology approaches is crucial for further developments of sustainable land-use planning.

\section{Conclusion}

The environmental change caused worldwide by the decoupling of energy flows and land uses urges societies to recover the former 'landscape efficiency', i.e. the socio-economic satisfaction of human needs while maintaining the landscape ecological functionality needed to ensure ecosystem services of all types (48). Depending on the energy storage-distribution $(E \cdot I)$, and how these energy flows are imprinted in the landscape $(L)$, agroecosystems may either enhance or decrease biodiversity $(40)$. Since the lack of an integrated management of energy flows and land-uses is part of the current global ecological crisis, its recovery becomes crucial for sustainable human-transformed landscapes. As Margalef suggested (31), 'the patterns of energy distribution ' shaped by farmer's knowledge (i.e. the distribution of energy flows according to an aim) and labour (i.e. the energy investments to maintain the agroecosystem's funds along time) have been determinant to understand the locations of bird and butterfly species richness and abundance in Mediterranean cultural landscapes.

The landscape scale is crucial for managing the challenge of increasing agricultural production while improving the state of the environment through a climate-smart and resilient farming transition. Neither agroecological intensification nor the application of a circular economy to agriculture will be possible without a rearrangement of the landscape complexity that allows closing their main biophysical cycles and improving their ecoefficiency. This innovative line of research aims at contributing to the economic and environmental viability of scaling up organic agriculture, and of agriculture in general. This is viable through the sustainable design of human-transformed landscapes that allow closing the socio-metabolic cycles, reducing non-external inputs dependence, and improving ecological processes to maintain biodiversity. 


\section{Materials and Methods}

Study area

With $3,200 \mathrm{~km}^{2}$ and a population of 4.5 million, the Barcelona Metropolitan Region (BMR) is one of the most densely populated regions in Europe (Fig. 4 ). However, this region still houses several important natural and semi-natural areas featuring considerable ecological diversity and valuable biocultural landscapes. Contrasting topography (elevation ranges from 0 to $1700 \mathrm{~m}$ a.s.l.) and climate (with gradients NE-SW from moist to dry and NE-SW from less to more continental) bring about a greater variability than that found in general Mediterranean conditions, which is responsible for the high biodiversity of this highly humantransformed territory. The region covers more than 40 habitat types of European interest (according to 92/43 EU Directive), including natural (forests, scrublands and grasslands; $60 \%$ of the region) and seminatural habitats (croplands; 21\%).

[Insert Figure 4 here]

ELIA model

$E L I A$ is an energy-information-landscape integrated analysis resulting from a mathematical model (see $\mathbf{2 4}$ for a detailed methodological description, and Annex B inSupplementary Information ). It combines the landscape functional structure $(L)$ with the interlinking pattern of energy flows driven by farming $(E$ ) and the information carried by them $(I)$, as a proxy of the potential biodiversity located in cultural landscapes. ELIA allows to interrelate the three indicators $(E, I, L)$ accounted in a spatial-explicit manner in each unit of analysis (i.e. transects) of digital land cover maps, to then relate them with georeferenced biodiversity data (Fig. 4 ).

Agroecosystem's energy storage (Fig. 5a ) is seen as the harnessing of dissipation thanks to the farmers' activity that generates and increases energy loops $(\mathbf{3 0})$. Farmers' energy reinvestment $(E)$ also means that this energy looping does not occur randomly across space and time, because it is driven by information $(I)$. Depending on the information delivered by farmers, the energy flows are redistributed in one or another way with different intensities across the agroecosystem. It is because energy carriers flow across different land uses following a deliberate pattern that they 'imprint' a specific land cover mosaic $(L)$ that we recognize as a cultural landscape (Fig. 5b ). The resulting mathematical model (24) allows calculating a three-dimensional relationship among $E, I$ and $L$ (Fig. 5c ), starting from the interaction between metabolic fluxes and landuses which give rise to specific human-transformed landscapes. It can be expressed combining the landscape functional structure with the complexity of the interlinking pattern of energy flows (their 'loopiness') and the information carried by them (49), taken as a biodiversity predictor in cultural landscapes:

$$
\mathrm{ELIA}=\left(\frac{(E I) \mathrm{L}}{\max \{\mathrm{EI}\} a}\right)^{1 / 3}
$$

Where $E$ is the energy storage, $I$ is the information carried by the network of energy flows and $L$ is the energy 'imprint' in the landscape functional structure $(\mathbf{2 4})$. Lis measured as the landscape pattern (landcover heterogeneity) and improved including the landscape processes (ecological connectivity). According to the $E L I A$ model, $\max \{\mathrm{EI}\} e=0.6169$ (Annex B ). Once we have the maximum $E I$ to structure the landscape, we can add the landscape functional structure $(L)$. ELIA values theoretically range from 0 to 1.

\section{[Insert Figure 5 here]}

The socio-metabolic analysis is based on an energy flow-fund approach of agroecosystems (50 ) of the BMR, using data from the Spanish Ministry of Agriculture and the Catalan Statistics Institute (44). The landscape composition and configuration has been calculated from the 2009 Land Cover Map of Catalonia (www.creaf.uab.es/mcsc/).

Species studied 
Birds and butterflies are recognized biodiversity indicators both in natural and human-modified landscapes. Their use as bioindicators comes from the variability within species and their ability to respond fast to environmental changes; including agricultural intensification and land abandonment $(\mathbf{1 2}, \mathbf{1 3}, \mathbf{1 4}, \mathbf{5 1})$. We obtained butterfly data from the Catalan Butterfly Monitoring Scheme (CBMS; $h t t p: / / w w w . c a t a l a n b m s . o r g /)$ running for the last 25 years (thus accounting for variable data length). The survey consists of a network of sites where visual counts of adult butterflies along transects are undertaken by volunteers. In each transect butterflies' surveys are done weekly during the flight period of imagos (March-September) along lineal transects of ca. $700-2500 \mathrm{~m}$ length (mean and median length $=1715$ and $2010 \mathrm{~m}$ respectively, wide $5 \mathrm{~m}$ ). Each transect is divided in smaller sections per dominant habitat type, leading to 6 to 14 sections per transect. Number of individuals (i.e. observations) are then recorded per species in each section, and then summarized per transect. We used 91 transects for the BMR (2009). In the case of birds, we obtained data from the Catalan monitoring scheme of common birds (SOCC;www.giraffa.co/ico-catalan-ornithological-institute/). Transects consist on a 3 -km track with six sections of $600 \mathrm{~m}$. Along these, the observers record bird observations and auditions, and then summarize data per transect. Two yearly censuses are performed for breeding species (April-May and May-June), and two for wintering species (December and January). We used 23 transects for the BMR (2009).

Landscape factors

A relatively recent (2009) land cover map of the BMR was used to assess landscape functional structure in the nearby of both butterfly and bird transects. These biodiversity databases consist in 91 transects monitored to get data of birds (linear buffer: $500 \mathrm{~m}$ ), and 23 transects monitored to obtain data of butterflies (circular buffer: $750 \mathrm{~m}$ ). In these buffers (Fig. 2 ), a set of landscape metrics of landscape composition and configuration were obtained using SIG (ArcGIS) methods. Regarding landscape composition, we calculated the proportion of main land cover categories (Forest, Scrubland, Cropland and Built-up) per buffer. Regarding landscape configuration, we obtained landscape heterogeneity (i.e. land cover evenness), edge density (i.e. the sum of edge length divided by buffer area), polygon density (i.e. the amount of patches per buffer area), largest patch index (i.e. the area percentage of the largest patch in the buffer), effective mesh size, a defragmentation measure proposed by Jaeger (52), and ecological connectivity, inferred from the ecological connectivity index proposed by Marull and Mallarach (53).

Statistical analyses

As a test of ELIA against biodiversity data components, we used the observed abundance (i.e. total number of butterfly observations) and species richness of butterflies and birds in the study transects. In order to disentangle the direct and indirect effects on biodiversity of energy storage and distribution, and of landscape composition and configuration, Structural Equation Models (SEM) were built for each of the studied biodiversity groups (butterflies, and breeding and wintering birds). Specific SEM were performed for species richness and abundance of all butterfly species clumped together and, in the case of birds, separately for nesting and wintering species. SEM considered the direct effects of the three ELIA components $(E, I, L)$ and their indirect effects reflected in landscape composition $(\mathrm{Cm})$ and configuration $(\mathrm{Cn})$. In order to reduce the number and the redundancy of variables in the SEM, we performed a Principal Component Analysis $(\mathrm{PCA})$ on $\mathrm{Cm}$ and $\mathrm{Cn}$ variables (Table $\mathbf{1}$ ). Analyses were performed using the SEM package in R (55).

\section{Acknowledgments}

This work has been supported by the research project BIOLANDSCAPEs 'Agro-ecological History for Designing Sustainable Landscapes. Case studies from the Mediterranean World' funded by the Spanish Ministry of Science, Innovation and Universities with the European Union FEDER funds (RTI2018-093970B MCIU/AEI/FEDER, UE). We thank the volunteers that participate in the bird (CBBS) and butterfly (CBMS) monitoring schemes in Catalonia. CBBS and CBMS are funded by the Catalan Government and are run by the Catalan Ornithological Institute and the Museum of Natural Sciences of Granollers, respectively.

\section{References}


1. A. T. Grove, O. Rackham, The Nature of Mediterranean Europe. An Ecological History (Yale University Press, 2001).https://books.google.es/books?id=trcsOyzKvRwCEprintsec $=$ frontcoverËdq=4.\%09Grove + AT,+ Rackham + AmMBHQ5MAeQQ6AEIKzAA\#v=onepage\& $q=4 . \% 09$ Grove\%20AT\%2C\%20Rackham\%200\%20The\%20Nature\%20of\%

2. M. Giampietro, K. Mayumi, A. H. Sorman, Energy Analysis for Sustainable Future: Multi-Scale Integrated Analysis of Societal and Ecosystem Metabolism (Routledge, 2013).https://books.google.es/books?id=TQatE9J4ez8CËrintsec $=$ frontcover\& $d q=$ Energy + Analysis + for + Sustainable + . Scale + Integrated + Analysis + of + Societal + and + Ecosystem + MetabolismEGhl $=e s \&$ sa $=$ XÉved $=0$ ahUKEwihO_ enzJzmAhXC8OAKHQh1AOIQ6AEIKzAA\#v=onepage\& $q=$ Energy\%20Analysis\%20for\%20Sustainable\%20Future\%3A Scale\%20Integrated\%20Analysis\%20of\%20Societal\%20and\%20Ecosystem\%20Metabolism\&f $=$ false

3. S. Sterling, A. Ducharne, Comprehensive data set of global land cover change for land surface model applications. Glob. Biogeochem. Cycles 22 (3),1-20 (2008).https://doi.org/10.1029/2007GB002959.

4. E. C. Ellis, K. K. Goldewijk, S. Siebert, et al., Anthropogenic transformation of the biomes, 1700 to 2000. Glob. Ecol. Biogeogr. 19 (5), 589-606 (2008).https://doi.org/10.1111/j.1466-8238.2010.00540.x.

5. N. Newbold, L. N. Hudson, A. Purvis, Global effects of land use on terrestrial biodiversity. Nature 520, 45-50 (2015).https://doi.org/10.1038/nature14324.

6. IPBES, Global Assessment Report on Biodiversity and Ecosystem Services (Bonn, 2019). Available athttps://ipbes.net. Deposited 4 December 2019.

7. P. González-Moreno, J. Pino, D. Carreras, et al., Quantifying the landscape influence on plant invasions in Mediterranean coastal habitats. Landscape Ecol. 28, 891-903 (2013).https://doi.org/10.1007/s10980013-985\%-1.

8. M. Gaertner, J. R. U. Wilson, M. W. Cadotte, et al., Non-native species in urban environments: patterns, processes, impacts and challenges. Biol Invasions 19(12), 3461-3469 (2017).https://doi.org/10.1007/s10530-017-1598-7.

9. M. Vilà, I. Ibáñez, Plant invasions in the landscape. Landscape Ecol. 26, 461-472 (2011).https://doi.org/10.1007/s10980-011-9585-3.

10. C. Basnou, J. Iguzquiza, J. Pino, Examining the role of landscape structure and dynamics in alien plant invasion from urban Mediterranean coastal habitats. Landscape Urban Plan. 136, 156-164 (2015).https://doi.org/10.1016/j.landurbplan.2014.12.001.

11. M. L. McKinney, Urbanization as a major cause of biotic homogenization. Biol. Conserv.127, 247-260 (2006).https://doi.org/10.1016/j.biocon.2005.09.005.

12. K. C. Santos, J. Pino, F. Rodà, et al., Beyond the reserves: The role of non-protected rural areas for avifauna conservation in the area of Barcelona (NE of Spain). Landsc. Urban Plan. 84, 140-151 (2008).https://doi.org/10.1016/j.landurbplan.2007.07.004.

13. Y. Melero, C. Stefanescu, J. Pino, General declines in Mediterranean butterflies over the last two decades are modulated by species traits.Biol. Conserv. 201, 336-342 (2016).https://doi.org/10.1016/j.biocon.2016.07.029.

14. C. Stefanescu, J. Carnicer, J. Peñuelas, Determinants of species richness in generalist and specialist Mediterranean butterflies: the negative synergistic forces of climate and habitat change.Ecography 34(3), 353-363 (2010).https://doi.org/10.1111/j.1600-0587.2010.06264.x.

15. V. Devictor, C. van Swaay, T. Brereton, et al., Differences in the climatic debts of birds and butterflies at a continental scale.Nat. Clim. Change 2, 121-124 (2012).https://doi.org/10.1038/NCLIMATE134\%.

16. C. Sirami, N. Gross, A. B. Boillod, Increasing crop heterogeneity enhances multitrophic diversity across agricultural regions. P. Nat. Acad. Sci. USA 116(33), 16442-16447 (2019).https://doi.org/10.1073/pnas.1906419116.

17. Y. Melero, C. Stefanescu, S. C. F. Palmer, et al., The role of the urban landscape on species with contrasting dispersal ability: Insights from greening plans for Barcelona. Landsc. Urban Plan. 195, on-line first (2019)https://doi.org/10.1016/j.landurbplan.2019.103707

18. Haberl, H., The Energetic Metabolism of Societies. Part I: Accounting Concepts. J. Ind. Ecol. 5, 107136 (2001).https://doi.org/10.1162/108819801753358481.

19. Wrbka T., Erb K. H., Schulz, N. B., et al., Linking pattern and process in cultural landscapes. An empirical study based on spatially explicit indicators. Land Use Policy 21(3), 289-306 (2004).htt- 
ps://doi.org/10.1016/j.landusepol.2003.10.012.

20. Huston, M. A., Disturbance, productivity, and species diversity: empiricism vs. logic in ecological theory. Ecology 95(9), 2382-2396 (2014).https://doi.org/10.1890/13-1397.1.

21. Perfecto, I., Vandermeer, J., The agroecological matrix as alternative to the landsparing/agriculture intensification model. P. Nat. Acad. Sci. USA 107(13), 5786-5791 (2010).https://doi.org/10.1073/pnas.090545510\%.

22. Loreau, M., Mouquet, N., Gonzalez, A., Biodiversity as spatial insurance in heterogeneous landscapes. P. Nat. Acad. Sci. USA100(22), 12765-12770 (2010).https://doi.org/10.1073/pnas.2235465100.

23. Swift, M. J., Izac, A. M. N., van Noordwijk, M., Biodiversity and ecosystem services in agricultural landscapes - are we asking the right questions? Agr. Ecosyst. Environ. 104(1), 113-134 (2004).https://doi.org/10.1016/j.agee.2004.01.013.

24. Marull, J., Font, C., Padró, R., et al., Energy-Landscape Integrated Analysis: A proposal for measuring complexity in internal agroecosystem processes (Barcelona Metropolitan Region, 1860-2000).Ecol. Indic. 66, 30-46 (2016b).https://doi.org/10.1016/j.ecolind.2016.01.015.

25. Matthews, R., Selman, P., Landscape as a focus for integrating human and environmental processes. J. Agric. Econ. 57, 199-121 (2006).https://doi.org/10.1111/j.1477-9552.2006.00047.x.

26. Parrotta, J. A., Trosper, R. L. (eds.), Traditional forest-related knowledge: sustaining communities, ecosystems and biocultural diversity (Springer, 2012).https://books.google.es/books?id=a3fAsBeLwNACEjpg=PA613Edq=26.\%09Parrotta, + J. + A., + Trosper,$+R .+L .,+$ related + knowledge $:+$ sustaining + communities, + ecosystems + and + biocultural + diversity $+($ Springer,$+2012 \mathscr{E} h l=c a \& s a=X$ jCrKPmAhW-BWMBHSIaAnkQ6AEIMTAB\#v=onepageEq=26.\%09Parrotta\%2C\%20J.\%20A.\%2C\%20Trosper\%2C\% related\%20knowledge\%3A\%20sustaining\%20communities\%2C\%20ecosystems\%20and\%20biocultural\%20diversity\%20(Sp

27. Morowitz, H. J., The Emergence of Everything: How the World Became Complex (Oxford University Press, 2002).https://books.google.es/books? id=Unw8DwAAQBAJEpg =PR4\&dq=The+Emergence +of + Everything: $+H o$ qC3gQ6AEIJzAA\#v=onepage6q=The\%20Emergence\%20of\%20Everything\%3A\%20How\%20the\%20World\%20Became\%

28. Gladyshev, G. P., On thermodynamics, entropy and evolution of biological systems: what is life from a physical chemist's viewpoint.Entropy 1, 9-20 (1999).https://doi.org/10.3390/e1020009.

29. Schrödinger, E., What is Life? (Cambridge University Press, 1944).https://books.google.es/books?id=hP9-WIEyv8cCEprintsec =frontcover\& $d q=29 . \% 09$ Schr\% C3\%B6dinger + What + AKHepmCc0Q6AEIZTAG\#v=onepage $6 q=29 . \% 09 S c h r \% C 3 \%$ B6dinger\%20What\%20is\%20Life\%3FEf=false

30. Ulanowicz, R. E., Some steps toward a central theory of ecosystem dynamics. Comput. Biol. Chem. 27(6), 523-530 (2003).https://doi.org/10.1016/S1476-9271(03)00050-1.

31. Margalef, R., Teoría de los sistemas ecológicos (Publicacions de la Universitat de Barcelona, 1991).https://books.google.es/books? id =c84Me5PfQJoCEpg =PA283\&dq=Margalef,$+R .,+$ Teor\%C3\%ADa + de + los + sistemas + ec

32. González-Bernáldez, F., Ecología y paisaje (Editorial Blume, 1981).

33. Marull, J., Font, C., Tello, E., et al., Towards an Energy-Landscape Integrated Analysis? Exploring the links between socio-metabolic disturbance and landscape ecology performance (Mallorca, Spain, 1956-2011). Landsc. Ecol. 31, 317-336 (2016a).https://doi.org/10.1007/s10980-015-0245-x.

34. Haberl, H., K. Erb, K. H., Krausmann, F., et al., Quantifying and mapping the human appropriation of net primary production in earth's terrestrial ecosystems. P. Nat. Acad. Sci. USA 104(31), 12942-12947 (2007).https://doi.org/10.1073/pnas.0704243104.

35. Krausmann, R., Erb, K. H., Gingrich, S., et al., Global human appropriation of net primary production doubled in the 20th century.P. Nat. Acad. Sci. USA 110(25), 10324-10329 (2013).https://doi.org/10.1073/pnas.1211349110.

36. Barnes, B., Sidhu, H. S., Roxburgh, S. H., A model integrating patch dynamics, competing species and the intermediate disturbance hypothesis. Ecol. Model . 194, 414-420 (2006).https://doi.org/10.1016/j.ecolmodel.2005.10.040.

37. Marull, J., Tello, E., Bagaria, G., et al., Exploring the links between social metabolism and biodiversity distribution across landscape gradients: A regional-scale contribution to the land-sharing versus land sparing debate. Sci. Total Environ . 619-620, 1272-1285 (2018).https://doi.org/10.1016/j.scitotenv.2017.11.196. 
38. Peterseil, J., Wrbka, T., Plutzar, C., et al., Evaluating the ecological sustainability of Austrian agricultural landscapes-the SINUS approach. Land Use Policy 21(3), 307-320 (2004).https://doi.org/10.1016/j.landusepol.2003.10.011.

39. Gershenson, C., Fernández, N., Complexity and information: measuring emergence, self-organization, and homeostasis on multiple scales. Complexity 18(2), 29-44 (2012).https://doi.org/10.1002/cplx.21424.

40. Marull, J., Herrando, S., Brotons L., et al., Building on Margalef: Testing the links between landscape structure, energy and information flows driven by farming and biodiversity. Sci. Total Environ . 674, 603-614 (2019a).https://doi.org/10.1016/j.scitotenv.2019.04.129.

41. Van Swaay, C. A. M., van Strien, A., Harpke, A., et al., The European butterfly indicator for grassland species 1990-2011. Report VS2012.019, De Vlinderstichting (Wageningen, 2012). Available athttps://www.eea.europa.eu/data-and-maps/data/external/european-grassland-butterfly-indicator Deposited 07 December 2019.

42. Thomas, J. A., Monitoring change in the abundance and distribution of insects using butterflies and other indicator groups. Philos. Trans. R. Soc. B 360, 339-357 (2005).https://doi.org/10.1098/rstb.2004.1585.

43. Inger, R., Gregory, R., Duffy, J. P., et al., Common European birds are declining rapidly while less abundant species' numbers are rising.Ecol. Lett. 18, 28-36 (2015).https://doi.org/10.1111/ele.12387.

44. Cattaneo, C., Marull, J., Tello, E., Landscape Agroecology. The Dysfunctionalities of Industrial Agriculture and the Loss of the Circular Bioeconomy in the Barcelona Region, 1956-2009.Sustainability 10(2), 1-22 (2018).https://doi.org/10.3390/su10124722.

45. Tscharntke, T., Clough, Y., Wanger, T. C., et al., Global food security, biodiversity conservation and the future of agricultural intensification. Biol Conserv . 151, 53-59 (2012).https://doi.org/10.1016/j.biocon.2012.01.068.

46. Schaffartzik, A., Mayer, A., Gingrich, S. et al., The global metabolic transition: Regional patterns and trends of global material flows, 1950-2010. Global Environ. Chang . 26, 87-97 (2014).https://doi.org/10.1016/j.gloenvcha.2014.03.013.

47. Guzmán, G. I., González de Molina, M., Preindustrial agriculture versus organic agriculture: The land cost of sustainability.Land Use Policy 26(2), 502-510 (2009).https://doi.org/10.1016/j.landusepol.2008.07.004.

48. Marull, J., Pino, J., Tello, E., et al., Social metabolism, landscape change and land use planning in the Barcelona Metropolitan Region.Land Use Policy 27(2), 497-510 (2010).https://doi.org/10.1016/j.landusepol.2009.07.004.

49. Marull, J., Font, C., "The Energy-Landscape Integrated Analysis (ELIA) of Agroecosystems" in Sociometabolic Perspectives on Sustainability of Local Food Systems. New Insights for Science, Policy and Practice, E. Fraňková, W. Haas, S. J. Singh, Eds. (Springer, 2017), pp. 103129.https://doi.org/10.1007/978-3-319-69236-4_4.

50. Tello, E., Galán, E., Sacristán, V. et al., Opening the black box of energy throughputs in agroecosystems: a decomposition analysis of final EROI into its internal and external returns (the Vallès County, Catalonia, c.1860 and 1999). Ecol. Econ . 121, 160-174 (2016).https://doi.org/10.1016/j.ecolecon.2015.11.012.

51. Vallecillo, S., Brotons, L., Herrando, S., Assessing the response of open-habitat bird species to landscape changes in Mediterranean mosaics. Biodivers. Conserv . 17,103-119 (2008).https://doi.org/10.1007/s10531-007-9233-z.

52. Jaeger, J., Landscape division, splitting index, and effective mesh size: new measures of landscape fragmentation. Landscape Ecol . 15(2), 115-130 (2000).https://doi.org/10.1023/A:100812932.

53. Marull, J., Mallarach, J. M., A GIS methodology for assessing ecological connectivity: application to the Barcelona Metropolitan Area. Landscape Urban Plan 71, 243-262 (2005).https://doi.org/10.1016/j.landurbplan.2004.03.00\%.

54. Marull, J., Cattaneo, C., Gingrich, S., et al., Comparative Energy-Landscape Integrated Analysis (ELIA) of past and present agroecosystems in North America and Europe from the 1830s to the 2010s. Agric. Syst . 175, 46-57 (2019b).https://doi.org/10.1016/j.agsy.2019.05.011. 
55. Fox, J., Nie, Z., Byrnes, J., SEM: Structural Equation Models. R Package Version 3.1-7 (2016).https://CRAN.R-project.org/package $=$ sem.

\section{Figures and Tables}

\section{Hosted file}

image1.emf available at https://authorea.com/users/301786/articles/431636-applyingthermodynamics-to-understand-the-links-between-energy-information-structure-and-

biodiversity-in-human-transformed-landscapes

Figure 1. Our conceptual approach is based on a fundamental idea of Margalef (1991) according to which the relationship between the external energy reinvested in the system $(E)$ and the spatial 'distribution pattern' $(I)$ of this energy flows need to be considered to understand how society affects the functional structure of cultural landscapes $(L)$. The figure shows: a small metabolic cycle (low $E, I$ and $L$ values); a large metabolic cycle (high $E$, and low $I$ and $L$ values); many small interconnected metabolic cycles (low $E$ , and high $I$ and $L$ values); and many large interconnected metabolic cycles (high $E, I$ and $L$ values). The latter case has stored more energy within and has greater capacity to organize the territory in a landscape mosaic $(L)$ that becomes less dependent on external energy flows.

\section{Hosted file}

image2.emf available at https://authorea.com/users/301786/articles/431636-applyingthermodynamics-to-understand-the-links-between-energy-information-structure-andbiodiversity-in-human-transformed-landscapes

Figure 2. Structural Equation Model (SEM, Annex A ) applied to the variables Total Butterfly Species Richness (TBSR) and Total Butterfly Observations (TBOB), taking into account: a ) the Energy-Landscape Integrated Analysis (ELIA ); and b ) the ELIA components (Energy Storage, E ; Energy Information, $I$, and Landscape Complexity, $L)$. We have included Landscape Composition $(\mathrm{Cm}$; in $\mathbf{a}$ and $\mathbf{b})$ and Landscape Configuration ( $\mathrm{Cn}$; only in a , because in bwe have included $L$ using Principal Component Analysis (Table $1)$.

\section{Hosted file}

image3.emf available at https://authorea.com/users/301786/articles/431636-applyingthermodynamics-to-understand-the-links-between-energy-information-structure-andbiodiversity-in-human-transformed-landscapes

Figure 3. Structural Equation Model (SEM; Annex A ) applied to the variables Breeding Bird Species Richness (BBSR) and Wintering Bird Species Richness (WBSP), taking into account: a)the Energy-Landscape Integrated Analysis (ELIA), and b)the ELIA components (Energy Storage, E ; Energy Information, $I$, and Landscape Complexity, $L)$. We have included Landscape Composition $(\mathrm{Cm}$; in $\mathbf{a}$ and $\mathbf{b})$ and Landscape Configuration ( $\mathrm{Cn}$; only in $\mathbf{a}$, because in bwe have included $L$ using Principal Component Analysis (Table $1)$. 


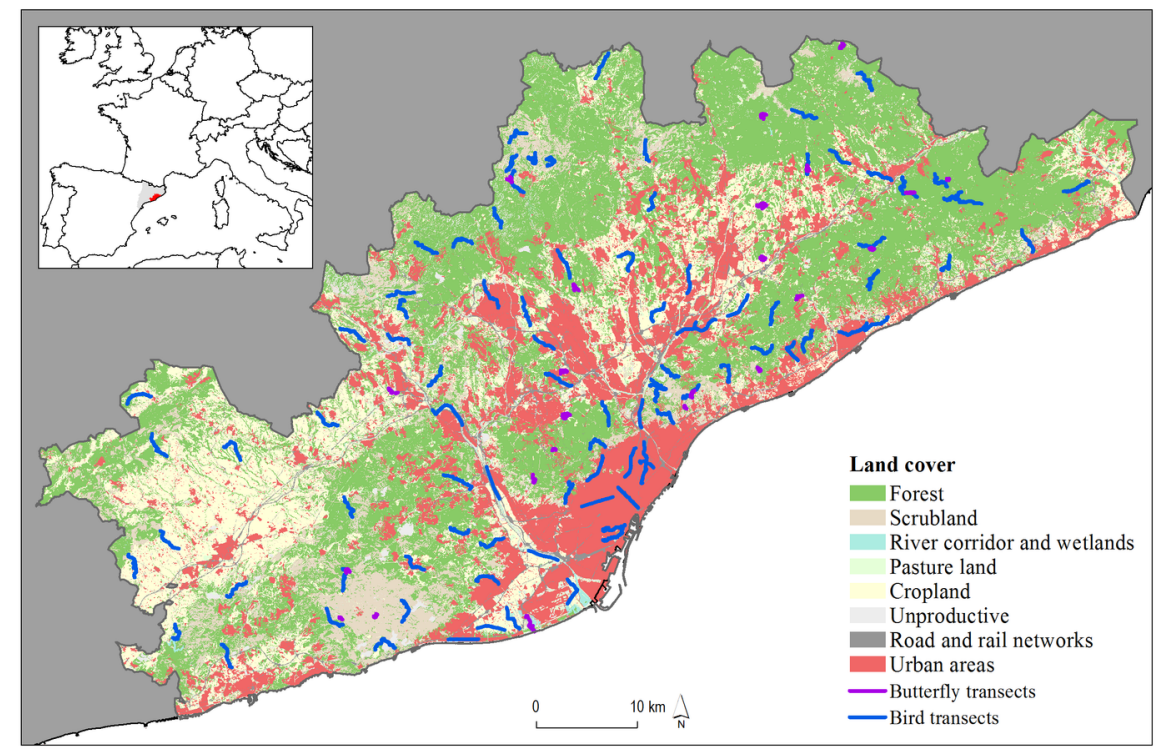

Figure 4. Butterfly transects (circular buffer: $750 \mathrm{~m} ; \mathrm{N}=23$ ) and bird transects (longitudinal buffer: $500 \mathrm{~m}$; $\mathrm{N}=91$ ) analysed in the Barcelona Metropolitan Region (NE Spain) and represented over a Land-cover Map (2009). Source: Catalan Butterfly Monitoring Scheme and Catalan Ornithological Institute datasets.

\section{Hosted file}

image5.emf available at https://authorea.com/users/301786/articles/431636-applyingthermodynamics-to-understand-the-links-between-energy-information-structure-andbiodiversity-in-human-transformed-landscapes

Figure 5. Methodological approach of the energy-information-structure model (see Annex B ): a)Graph model of the interlinked energy carriers flowing in an agroecosystem. b) From the graph model, we can calculate the energy investment $(E)$, the energy information $(I)$, and the energy 'imprint' in the landscape structure $(L)$. c) The resulting mathematical model allows to calculate a three-dimensional relationship among $E, I$ and $L$ (as an example five land-cover typologies are represented), conforming a particular human-transformed landscape.

\begin{tabular}{lllll}
\hline Landscape Configuration & Landscape Configuration & Landscape Configuration & Landscape Configuration & Landscape C \\
\hline Land Metric & Butterfly transects & Butterfly transects & Bird transects & Bird transect \\
& Cn1 & Cn2 & Cn1 & Cn2 \\
Heterogeneity & -0.406 & 0.341 & -0.503 & -0.083 \\
Edge Density & -0.434 & 0.244 & -0.522 & 0.059 \\
Polygon Density & -0.421 & 0.331 & -0.490 & -0.005 \\
Largest Path Index & 0.458 & -0.097 & 0.433 & -0.308 \\
Effective Mesh Size & 0.354 & 0.611 & 0.027 & -0.696 \\
Connectivity & 0.367 & 0.577 & -0.216 & -0.641 \\
Standard deviation & 2.084 & 0.857 & 1.794 & 1.280 \\
Proportion of variance & 0.724 & 0.122 & 0.536 & 0.273 \\
Cumulative Proportion & 0.724 & 0.846 & 0.536 & 0.809 \\
\hline
\end{tabular}




\begin{tabular}{lllll}
\hline Landscape Configuration & Landscape Configuration & Landscape Configuration & Landscape Configuration & Landscape C \\
\hline Land Metric & Butterfly transects & Butterfly transects & Bird transects & Bird transect \\
& Cn1 & Cn2 & Cn1 & Cn2 \\
Heterogeneity & -0.406 & 0.341 & -0.503 & -0.083 \\
Edge Density & -0.434 & 0.244 & -0.522 & 0.059 \\
Polygon Density & -0.421 & 0.331 & -0.490 & -0.005 \\
Largest Path Index & 0.458 & -0.097 & 0.433 & -0.308 \\
Effective Mesh Size & 0.354 & 0.611 & 0.027 & -0.696 \\
Connectivity & 0.367 & 0.577 & -0.216 & -0.641 \\
Standard deviation & 2.084 & 0.857 & 1.794 & 1.280 \\
Proportion of variance & 0.724 & 0.122 & 0.536 & 0.273 \\
Cumulative Proportion & 0.724 & 0.846 & 0.536 & 0.809 \\
\hline
\end{tabular}

Table 1. Principal Component Analysis (PCA) applied to the Landscape Composition ( $\mathrm{Cm})$ and the Landscape Configuration ( $\mathrm{Cn}$ ) variables used in the Structural Equation Model (SEM; Annex A ) for the butterfly and the bird transects observed in the Barcelona Metropolitan Region. 